Anat. Labor. of Prof. H. SETO, Tohoku University, Sendai.

\title{
Supplementary Study on the Fine Structure of the Oviduct and the Mesosalpinx in Man and their Innervation.
}

人邲管及び卵管間朕の微紐構造亚に神経分布飞関する知見補遗.

\author{
Shigeyoshi HATAKEYAMA 鼻 ll 重我。
}

(Received September 27, 1956.)

Microscopic studies for elucidating the fine structure and the innervation of the human oviduct and the mesosalpinx have been undertaken by many histologists since the end of the last century, induced by the physiological importance of scientific informations on these parts. Many noteworthy results have been reported of these studies, yet there seems to be some inadequacies still waiting clarification, especially in our know. ledge concerning the innervation of these parts. In fact, the older works by HERFF (1892), GAWRONSKY (1894), KÖSTIIN (1898), EBNER (1903), DAHL (1916) and MABUCHI (1924) merely betray the imperfection of the staining method they have availed of, and even the studies by HARTING (1929) and SAKAGUCHI (1939) utilizing tissue preparations stained with excellent silver methods contain some descriptions of doubtful accuracy. Of course, the distribution of vegetative nerves in these parts has been much cleared up by their studies, but concerning the sensory fibres and their terminations, RIES (1908) and CORYLLOS (1915) have reported on their discovery of PACINIan bodies in the submucosa of the oviduct and HARTING (1929) on the existence in rare cases of MEISSNER's bodies, while SAKAGUCHI has denied the existence of such corpuscular terminations, mentioning only of a small number of simple branched sensory terminations alongside the small blood vessels, betraying confusion among the reported results. More recently, LANDAU (1952) has pointed out the existence of myelinated thick sensory fibres in the oviduct.

Now, deseriptions of the innervation of the oviduct have been appearing in reports as cited above, but we hear nothing on the histological study of the nerve distribution of the mesosalpinx to date. The author of this paper has had of late the opportunity of studying the innervation of the oviduct and the mesosalpinx, at the same time making some supplements to the informations on the histology of these parts. My materials were taken from corpses of adult women, were fixed in $10 \%$ neutral formol solution for long time, cut into $40 \mu$ frozen cross-sections 
and stained with the excellent SETO's silver impregnation method in common use at this laboratory. The large series of most beautifully stained preparations thus obtained I subjected to minute microscopic examination and arrived at the following observations.

\section{Individual Observations.}

I will first give a description of the fine structure of the mesosalpinx, upon which there is so little literature available at present. This membrane represents an extension of the lig. latum, being formed by a duplicature of the peritoneum, as shown in Fig. 1, and is lined by the serosa of simple endothelial layer on both its surfaces. The subserosa consists of a very thin layer of fine connective tissue and fine smooth muscle bundles are found aggregated beneath it. Most of these bundles take longitudinal courses, but a fewer run diagonally or cross-wise. At the edge, this muscle layer passes over into the so-called subperitoneal muscle layer of the oviduct. Between the muscle layers of both the sides, the mesosalpinx is rather rich in loose connective tissue, through which arteries originating in the a. ovarica and veins running into the plexus spermaticus are found. Besides, we find fine muscle bundles here and there in this blood vessel layer too. These findings may be found clearly illustrated in Fig. 2, which shows Fig. 1 in higher magnification.

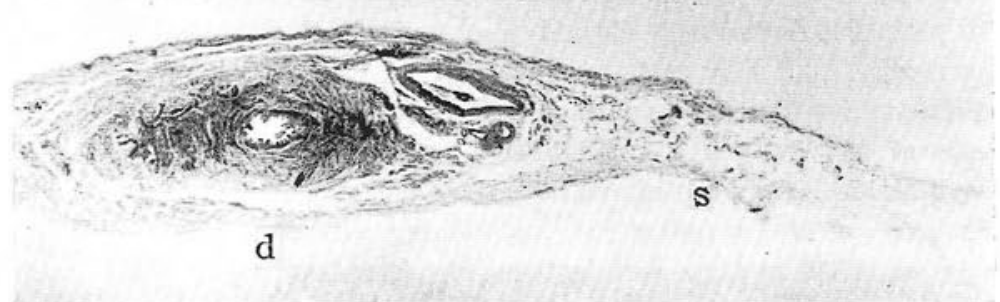

Fig. 1. A cross section through the isthmus of the human oviduct $(d)$ with the mesosalpinx $(s)$. SETO's impregnation. Photo $\times 7$.

In short, the above histological findings show that the mesosalpinx representing a duplicature of the peritoneum is formed of a smooth muscle tissue containing blood vessels at its core. Histologically speaking, the mesosalpinx is related to the oviduct just in the same manner as the mesometrium, representing a continuation of the lig. latum uteri, stands to the uterus.

In the mesosalpinx, especially near its abdominal end, we find frequent existence of tubules of the epoöphoron. These are in most cases, as shown in Fig. 3, small canals formed by a simple columnar or cubic 


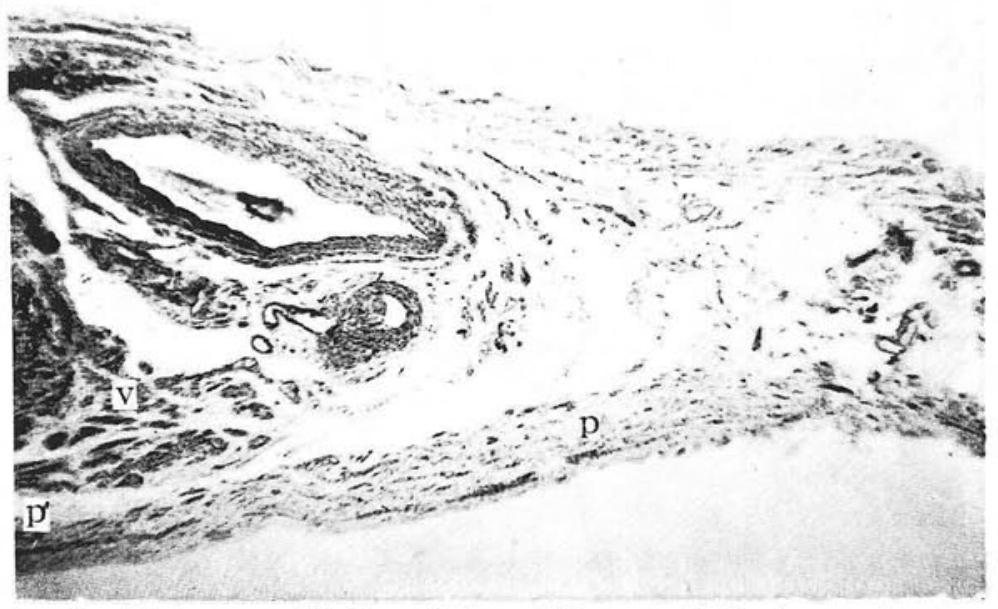

Fig. 2. Higher magnification of the middle part of Fig. 1. $p$ subperitoneal muscle layer of the mesosalpinx which passes over into the str. perivasculare of the muscularis of the oviduct $p^{\prime} ; v$ str. vasculare containing blood vessels and small muscle bundles. Same staining. Photo $\times 21$.

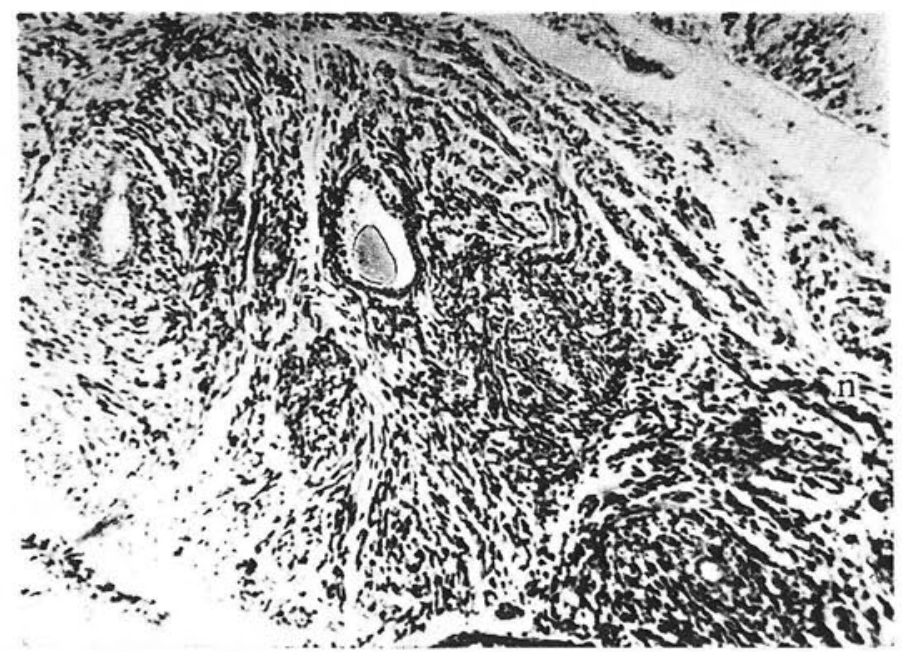

Fig. 3. Tubules of epoöpholon found in the human mesosalpinx in the lateral side. Details in the text. $n$ small nerve fibres. Same staining. Photo $\times 90$.

epithelium lined on the outside by muscle layer consisting of exceedingly well-developed circular or longitudinal smooth muscle bundles, representing rudimentary formations originating in WOLFF's body, as is well known. 
These epithelial canals are generally very narrow, but in some cases, their breadth is rather large.

The oviduct consists of a serosa, a subserosa, a tunica muscularis and a tunica mucosa, but the relative thicknesses of these layers are not uniform in different parts of the duct. For example, the mucosa and the blood vessels are well developed but the muscle layer is poor in the ampulla, while in the isthmus, the relative development of these layers is in an inverse relation, especially so as the nearer the uterus is approached (Fig. 4).

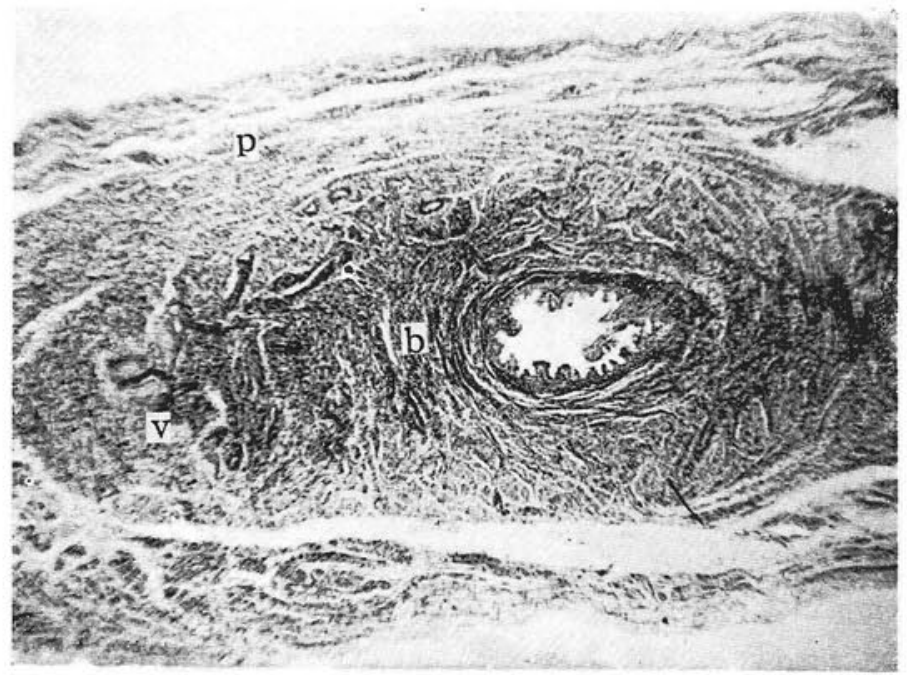

Fig. 4. Higher magnification of the isthmus of the human oviduct in Fig. 1. $p$ str. perivasculare; $v$ str. vasculare; $b$ str. submucosum; $\mathrm{m}$ mucosa provided with a few mucous folds. Same staining. Photo $\times 21$.

The subserosa is a thin layer of fine connective tissue in the oviduct quite as in the mesosalpinx. According to SCHRÖDER, however, it is said that the subserosa here consists of longitudinal muscle bundles and blood vessels running equally longitudinaily beneath it. My observations were nearly in agreement with this description of SCHRÖDER, but these layers of muscle fibres and blood vessels are layers found on the inside of what I call the subserosa, and since frequent and diversely running fine muscle fibre bundles are found in the SCHRÖDER's so-called blood vessel layer, too, these layers are to be regarded as belonging, not to the subserosa, but to the tunica muscularis (Figs. 1 and 4). The layer rich in blood vessels is to correspond to the so-called stratum vasculare of the tunica muscularis of the uterus, while the outer muscle layer should coin- 
cide with the so-called stratum perivasculare uteri. The bood vessels themselves are well developed enough in the abdominal part of the oviduct, but as the uterus is more approached, they become worse developed.

According to most of the past reports, the hitherto so-called tunica muscularis of the oviduct is said to comprise an outer longitudinal layer and an inner circular layer, of which the outer, consisting of muscle fibres running longitudinally and containing small blood vessels, is very powerfully developed in the oviduct wall lying within the uterus, becomes very attenuated in the isthmus but thickens again as the abdominal end is approached, forming there the muscular ground layer of the fimbriae ovaricae, while the inner layer of circularly running muscle fibre bundles is very thin in formation at the abdominal end, gains slowly in thickness in the isthmus and becomes more and more strongly developed on approaching the uterus. As I have observed, however, both these muscle layers equally contain muscle bundles running in various directions, so that it is quite impossible to see two layers of differently oriented muscle fibres in the muscularis here (Fig. 4). So, it is my impression that this stratum does not comprise two, but one sublayer and as a whole corresponds to the so-called stratum submucosum in the uterus.

From the above findings, we may conclude that the muscularis of the oviduct is similarly constructed as that of the uterus. 'Thus, it is clear that the oviduct, somewhat in disagreement from what has been reported in the past, is a muscular organ of similar structure as the uterus, only far smaller in size.

The mucosa of the oviduct consists of a delicate connective tissue, comprising a thin propria containing numerous spindle-formed fibrocytes and a simple epithelium. The cells forming this epithelium are low in height and cubic in form in the isthmus, but are taller and columnar in the ampulla. Some of the cells are ciliated and others not, resembling those in the epithelium of the uterus in this respect. The only difference is that mucous folds, not to be found in the uterine mucosa, are well developed in the oviduct.

As described in the preceding, the histological structure of the oviduct is quite in the same pattern as that of the uterus, though far smaller in dimensions. This fact can be easily understood if we recall that these two organs have the same embryological origin. Of course their physiological functions are different, the oviduct serving in forwarding the fertilized egg cell to the mucosa uteri, and the uterus in carrying on the pregnancy to completion in it, but if we take into account the not too low frequency of tubular pregnancy, it is no wonder that the two organs are so similar in general construction.

The nerves supplied to the oviduct, as is well known, consists of 
vegetative fibres originatiug in the plexus ovaricus and the plexus uterovaginalis, with a sprinkle of sensory fibres of spinal nature superadded. These nerve fibres run first in comparatively small nerve bundles into the blood vessels containing loose connective tissue forming the middle layer of the mesosalpinx, and then, upon reaching the oviduct, run into the intermediate layer containing longitudinally running blood vessels or the so-called stratum vasculare.

Now, as stated in the above, in the mesosalpinx, smooth muscle fibres are found not only around the blood vessel layer but also in the blood vessel layer itself, so we should find nerves distributed to innervate the muscles in this layer too. We expect nerves to be distributed also in relation with the epoöphoron. No report, however, on the innervation of the mesosalpinx has been ever published to date. Now that I have succeeded for the first time in shedding light on the distribution of vegetative as well as sensory fibres in the mesosalpinx, I will report my findings in the following.

The small nerve bundles proceeding through the middle layer of the mesosalpinx send out numerous fine branches in their courses into the smooth muscle layer lining it. These branches undergo further ramification and anastomosis in transit and finally develop into STÖHR's terminal reticula as in the cases of all common smooth muscle fibres. This net-

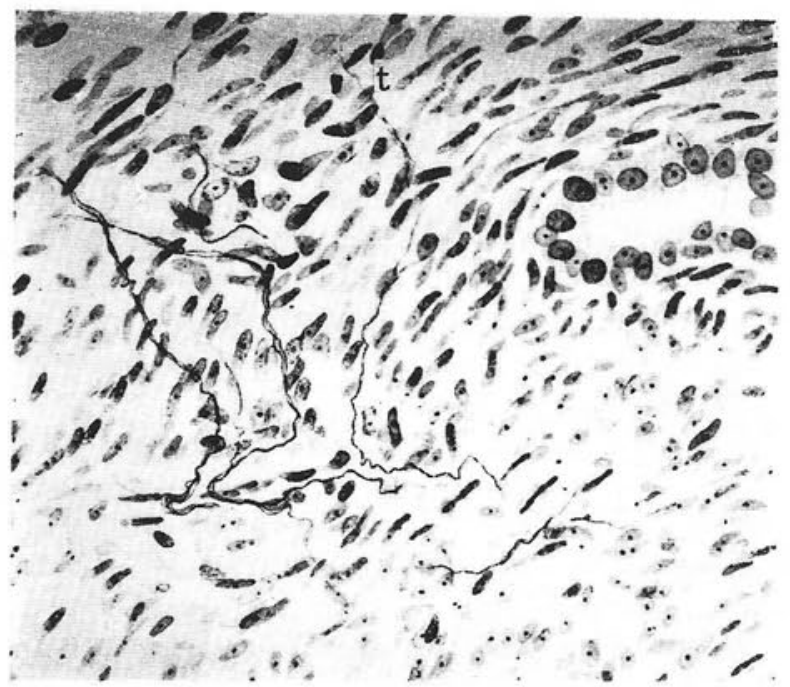

Fig. 5. Fine vegetative fibres distributed in the smooth muscle tissue surrounding a tubule of epoöpholon in the human mesosalpinx. $t$ vegetative terminal reticulum. Same staining. $\times 500$, reduced to $4 / 5$. 
work formation is also similarly observed around the tubules of epoöphoron. Fig. 5 shows the terminal distribution of vegetative nerve fibres found in variously oriented muscle bundles around a tubule of epoöphoron. The terminal reticula, as I have observed, come into contact with the muscle fibres but never penetrate into their protoplasma.

These small nerve bundles effect anastomosis also between the perivascular plexus formed around the blood vessels, especially, the arteries. In the blood vessels, I found very well developed terminal reticula spreading from the externa into the media, and showing forms in perfect uniformity with those in the blood vessels in other organs.

Sensory fibres were also found in existence here and there, sometimes consisting in very thick myelinated fibres as shown in Fig. 6. These fibres, upon approaching their terminations, part from the other fibres of the same bundle to run isolated courses, very frequently taking winding

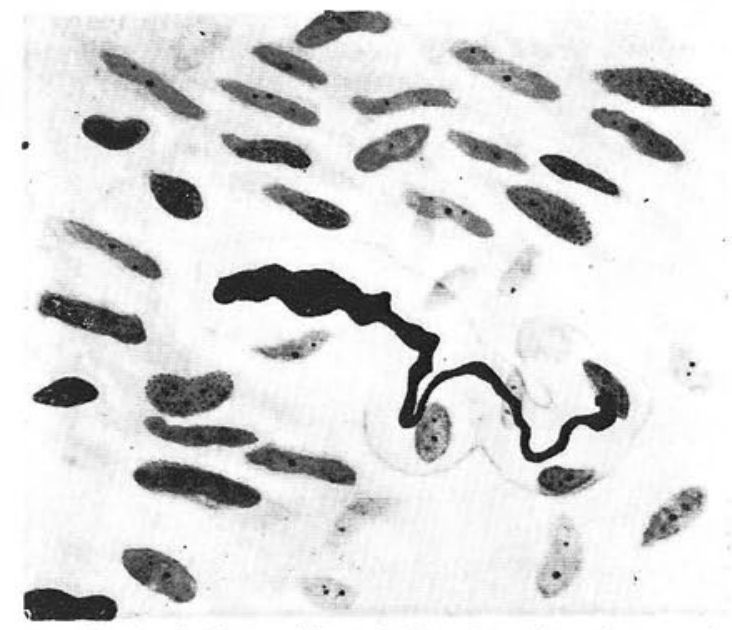

Fig. 6. A thick myelinated fibre found in the smooth muscle tissue of the human mesosalpinx. Same staining. $\times 1500$, reduced to $5 / 6$.

forms peculiar to sensory fibres. Then they either remain unbranched or branch out into 2 or 3 rami to pass over into their respective terminations. They usually terminate in the connective tissue between the muscle bundles (Fig. 7) or often around the blood vessels, especially, the small veins, but sometimes run further into the subserosa through the muscle layer, to come up close to the underside of the peritoneal epithelium (Fig. 8). Thus, the sensory fibres in this part generally end in very simple terminations, but such complex terminations as the terminal corpuscles as reported by RIES and CORYLLOS were never observed throughout my study. 


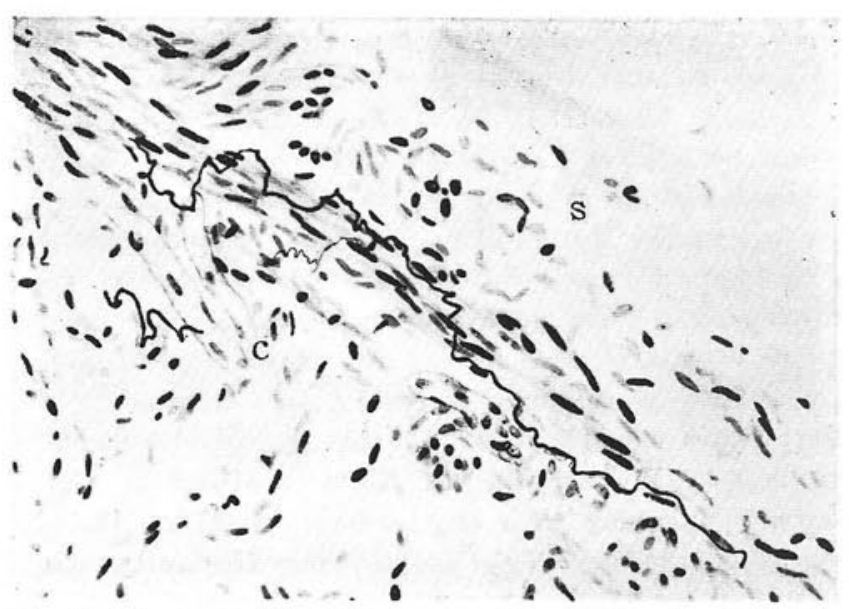

Fig. 7. A simple branched sensory termination found in the smooth muscle tissue of the human mesosalpinx. $s$ subserosa; $c$ capillaries. Same staining. $\times 320$, reduced to $1 / 2$.

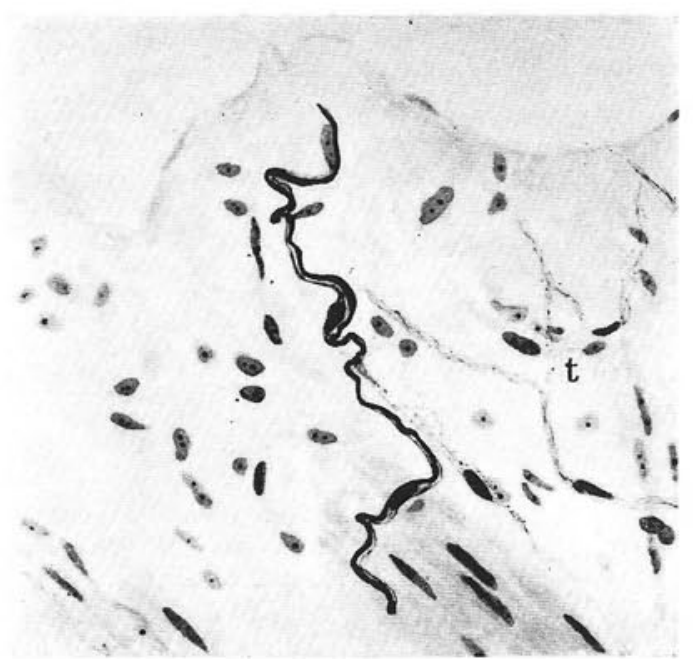

Fig. 8. An unbranched sensory termination formed subperitoneally in the human mesosalpinz. $t$ vegetative terminal reticulum; $m$ muscle tissue. Same staining. $\times 400$, reduced to $4 / 5$.

The nerve bundles accompanying the blood vessels running through the middle layer of the mesosalpinx go from the attachment of the membrane to the oviduct into the so-called stratum vasculare muscularis of the oviduct, then further branch out into fine rami and anastomose among 
themselves, and finally form the HARTING's so-called ground plexus. This plexus is much poorer in construction than the AUERBACH's plexus in the alimentary tract and I failed, as HARTING and SAKAGUCHI failed, to find anything like the nerve cells described by KÖSTLIN and GAWRONSKY. HARTING has called this ground plexus subperitoneal plexus, while SAKAGUCHI has located it in the adventitia, but actually it was found in my stratum vasculare. The failure of the two predecessors above in seeing the truth seems to be due to the insufficiency of their histological serutiny.

From the ground plexus formed in the stratum vasculare are sent out many nerve branches running out from this layer either outwards into the stratum perivasculare or inwards into the stratum submucosum. These branches never fail to make ramification and anastomosis many times in their courses and form a rather complicated nerve net system in the muscle layers. The nerve fibres coming through the stratum submucosum run further into the propria mucosae to form fine plexus proprius after further ramification and anastomosis (Fig. 9). The nerve plexuses are never

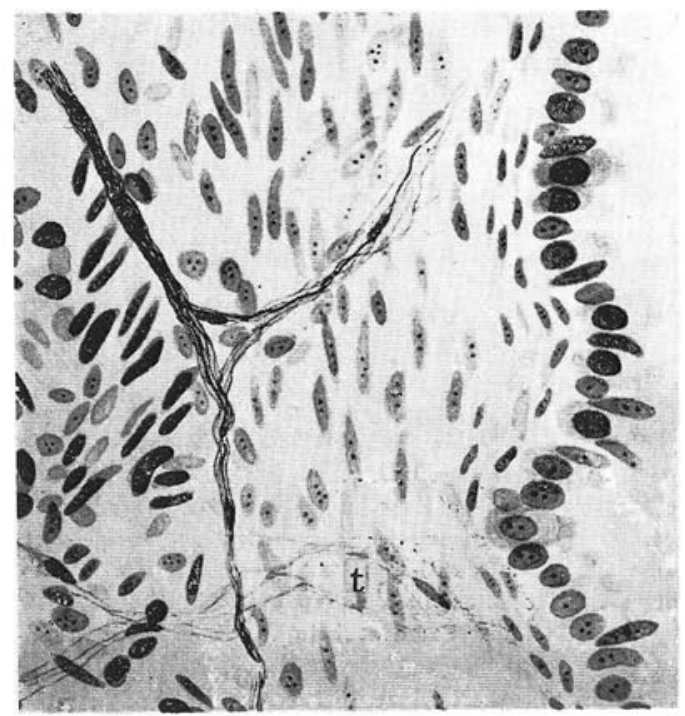

Fig. 9. Plexus proprius formed in the mucosa of the human oviduct. $t$ terminal reticulum distributed from the str. submucosum of the muscularis to the propria. Same staining. $\times 400$, reduced to $4 / 5$.

formed either in the muscularis or the propria in uniform strength, being very well developed in some places but only extremely loosely in other.

According to HARTING, the nerve fibres running into the propria 
mucosae penetrate from the ground plexus directly and vertically through the muscularis. Therefore, he says an essential difference is found between the fibres running toward the propria and those distributed within the muscularis, viewed from the histological standpoint. My observations, however, did not reveal such a difference, in agreement with what SAKAGUCHI has reported. HARTING also remarked that the nerve fibres coming into the mucosa were probably always of sensory nature, but my observations showed that most of them are non-myelinated fine fibres obviously of vegetative nature, and on this point also I take exception to the opinion of HARTING. Only, I have found not rarely a few number of thick sensory fibres and their terminations beside the vegetative fibres in the mucosa, as described below. That is to say, I have succeeded in demonstrating that nervous reception is possible in the mucosa of the oviduct.

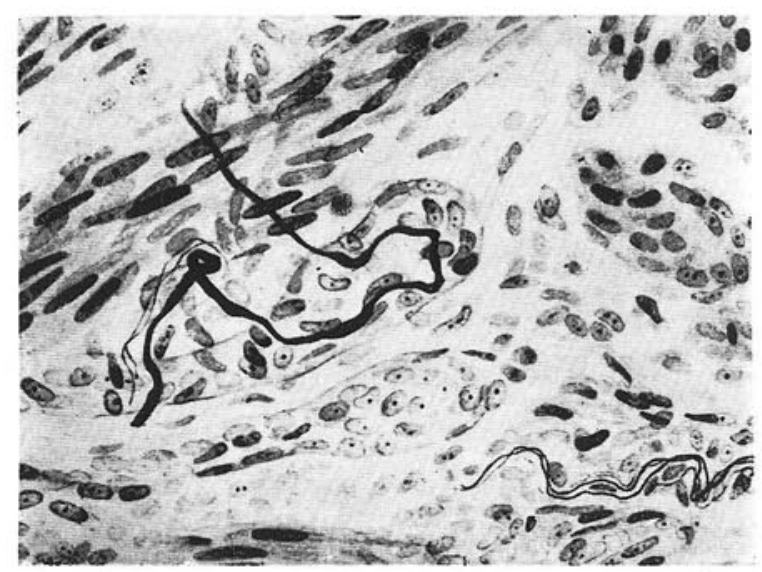

Fig. 10. An unbranched sensory termination found in the str. vasculare of the muscularis of the human oviduct. A thick sensory fibre running a special winding course around a small vein and showing a conspicuous change in size ends in a sharp point in the muscle tissue. Same staining. $\times 250$.

The vegetative fibres spreading out in the 3 sublayers of the muscularis of the oviduct finally end in typical terminal reticula (STÖHR) as such fibres do in any other organs and tissues and quite in a similar manner as in the mesosalpinx cited above. The vegetative fibres from the perivascular plexus around the blood vessels also form terminal reticula in the vascular walls (Fig. 11). The terminal reticula stand in contact control over the smooth muscle cells, but I never found them sending out side branches further through or into the cells. 


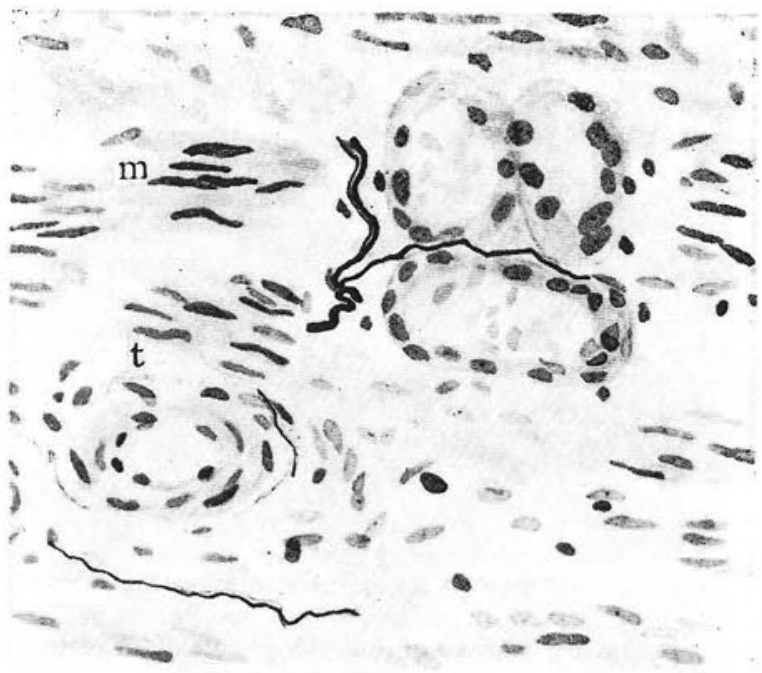

Fig. 11. A simple branched termination formed around small veins in the str. submucosum of the muscularis of the human oviduct. Details in the text. $m$ muscle tissue; $t$ terminal reticulum around a small artery. Same staining. $\times 400$, reduced to $4 / 5$.

As SAKAGUCHI has already reported, the vegetative fibres in the propria terminate in terminal reticula. These terminal reticula, beside having control over the fibrocytes in this part, run up closely beneath the epithelium and seem to come into control over it by basal contact (Fig. 9).

I have already pointed out that myelinated fibres are found in the nerve bundles running distalwards through the mesosalpinx. These sensory fibres run sometimes beyond the mesosalpinx into the oviduct, as LANDAU has lately illustrated. As to how these sensory fibres shape their terminations, SAKAGUCHI (1939) has already reported his discovery of simple branched terminations in the oviduct. In this, I am in agreement with SAKAGUCHI, but while he has announced these sensory terminations to be found only in the small blood vessels of the tunica muscularis and only on very rare occasions, I could detect rather frequently simple sensory terminations, not only around the blood vessels in the muscularis, but also in the muscularis itself, in the subserosa outside the stratum perivasculare and even in the propria mucosae. On the other hand, I could not detect any such complex corpuscular terminations as the PACINIan bodies described by RIES (1908) and CORYLLOS (1913) or the MEISSNER's tactile body allegedly found by HARTING (1929) in a mucous fold of the ampulla of the oviduct. Despite my rigorous search, 


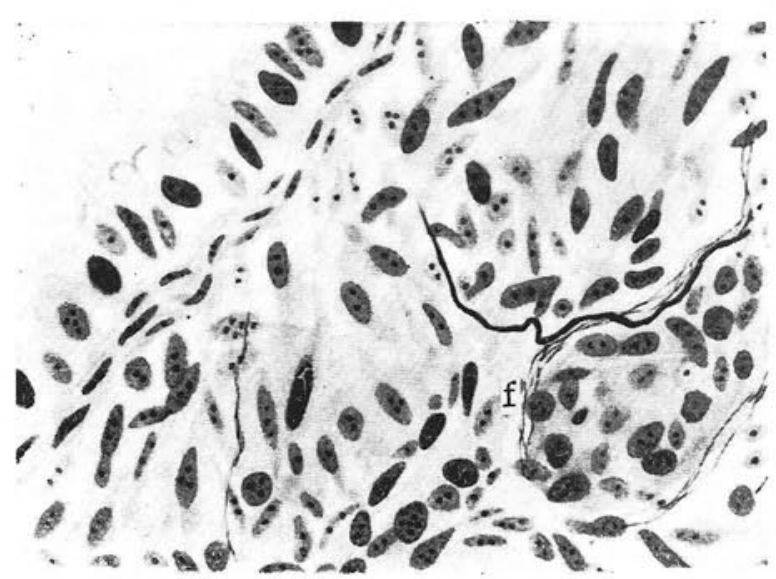

Fig. 12. An unbranched sensory termination found in the str. submucosum of the muscularis of the human oviduct. $f$ fine vegetative fibres running along a small vein. Same staining. $\times 400$.

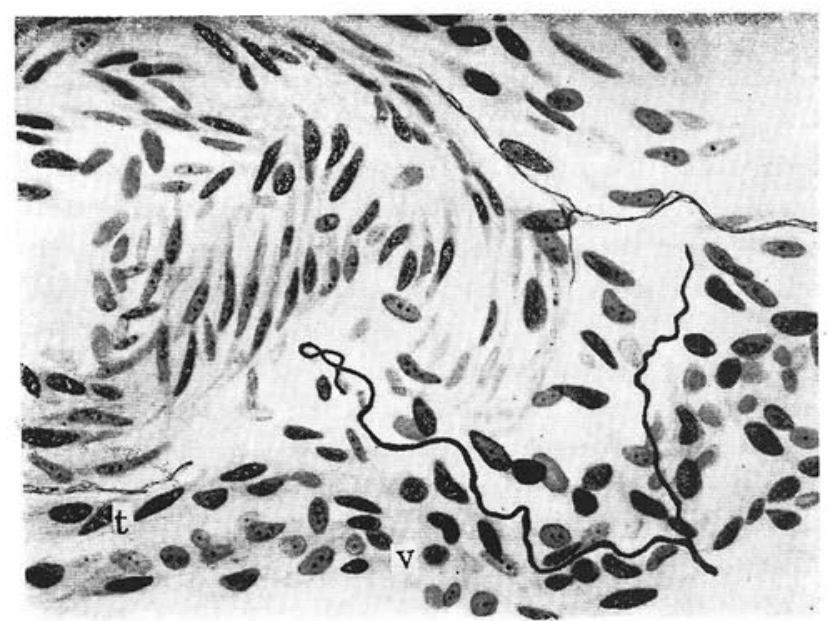

Fig. 13. A simple branched sensory termination formed around a small artery of the str. vasculare of the human oviduct. Details in the text. $t$ terminal reticulum; $v$ small vein. Same staining. $\times 400$, reduced to $5 / 6$.

I did not succeed either in finding the sensory intraepithelial fibres alluded to by GAWRONSKY (1894). In all probability, these represent only artefacts conjured up by defective staining.

In the following, I will give a detailed description of the sensory terminations I have observed in the oviduct. The myelinated sensory 
fibres, upon approaching their terminal areas, lose their myelin sheaths and often showing characteristic change in size and winding courses, end in unbranched or simple branched terminations of $2-3$ branches. These terminations are formed in the tunica muscularis much more frequently around the blood vessels than in the muscle tissue. Of the blood vessels, the veins seem to be much better provided with sensory terminations around them than the arteries.

Fig. 10 shows an unbranched sensory termination formed by a sensory fibre showing characteristic winding and change in size around a small vein in the tunica muscularis. The tip of its terminal fibre runs further into the muscle tissue to end bluntly therein. In Fig. 11, a simple branched termination formed similarly around a small vein in the muscularis is illustrated. The trunk fibre is here also of considerable size, but its terminal fibres are all cut short so that we cannot make out the ending mode of these fibres. An unbranched sensory termination formed around a small vein found in the muscularis close to the propria mucosae is illustrated in Fig. 12. The terminal fibre here shows not much change in size and it ends in a sharp point directed toward the propria. In Fig. 13. a sensory fibre that has run along a small vein is seen bifurcating into two branches, which separately go as far as to reach into the connective tissue of the tunica externa of a relatively thick artery and end

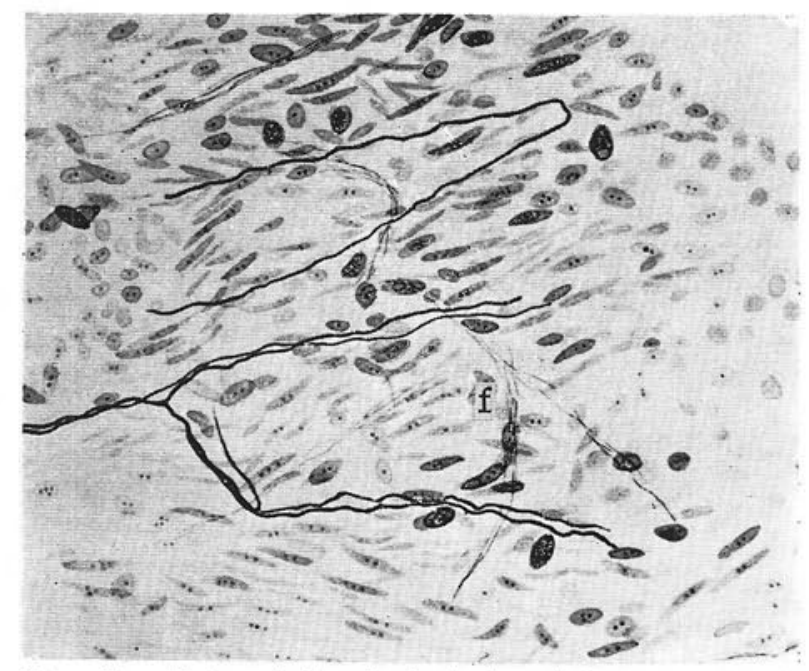

Fig. 14. Unbranched and simple branched sensory terminations distributed from the str. submucosum of the muscularis to the propria mucosae of the human oviduct. Details in the text. $f$ fine vegetative fibres. Same staining. $\times 400$, reduced to $2 / 3$. 


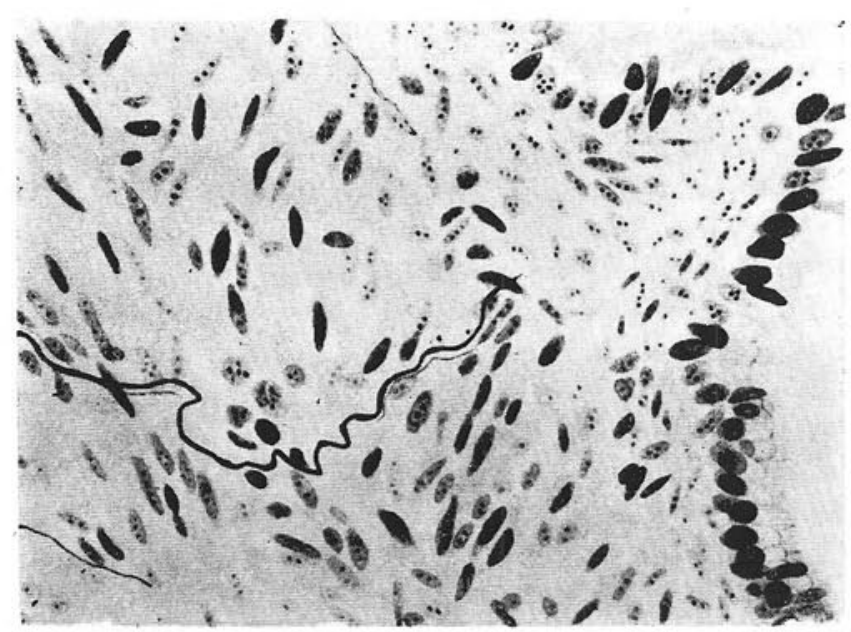

Fig. 15. An unbranched sensory termination ending in a sharp point in the propria mucosae of the human oviduct. Details in the text. Same staining. $\times 400$, reduced to $5 / 6$.

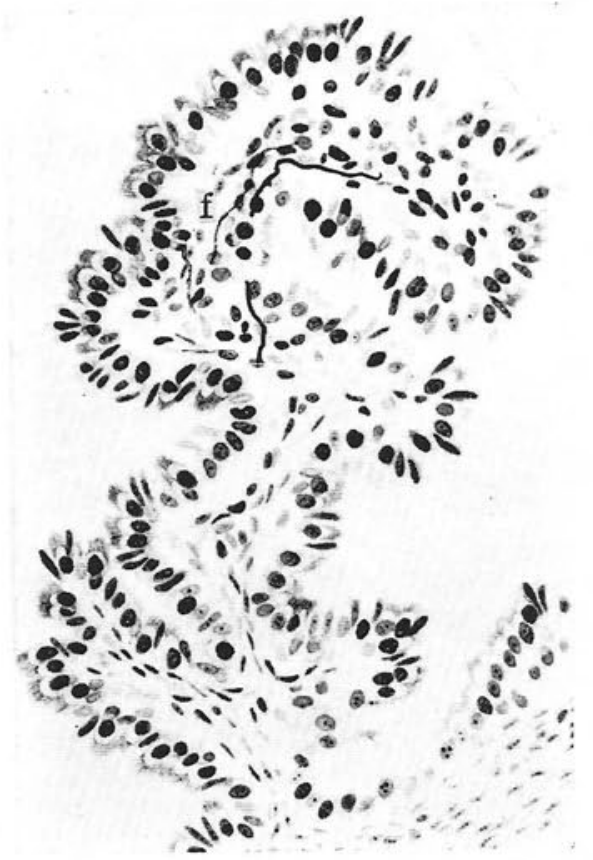

Fig. 16. An unbranched sensory termination ending in_a sharp point found in a mucous fold of the human oviduct. $f$ fine vegetative fibres. Same staining. $\times 300$, reduced to $2 / 3$. 
there bluntly, forming a simple branched termination. Both the branches take characteristic winding courses and that seen on the left describes a simple loop before ending.

Examples of sensory terminations found in the propria of the mucous membrane of the oviduct are illustrated in Figs. 14, 15 and 16. In Fig. 14, you see a few sensory fibres running out of the stratum submucosum muscularis toward the propria mucosae and respectively ending in unbranched or simple branched terminations in its connective tissue. These fibres show little perceptible change in size or winding courses. Fig. 15 illustrates a simplest-formed unbranched termination formed out of the stratum submucosum toward the mucous membrane, too. Here, the fibre shows a marked winding and a limited change in size, the terminal fibre ending nearly sharply. Fig. 16 shows an unbranched termination of a sensory fibre penetrating into a mucous fold and ending in a sharp point.

\section{Summary.}

The human mesosalpinx represents a duplicature of the peritoneum and chiefly consists of smooth muscle tissue containing blood vessels spreading out into the oviduct. The histological relation between the mesosalpinx and the oviduct is a similar one to that between the mesometrium and the uterus. The muscle fibres in it run oftener longitudinally, but not a small number of them are oriented diagonally or transversely. The tubules of the epoöphoron consist in small canals lined by a simple epithelium surrounded by well-developed circular or longitudinal smooth muscle bundles.

The oviduct is constructed of a serosa, a subserosa, a musscularis and a mucosa, the relative thickneses of these layers differing by positions. The muscularis can be divided into the outer and the inner layers with the SCHRÖDER's so-called blood vessel layer between them. The median layer rich in blood vessels may be taken to correspond to the stratum vasculare, the middle layer of the muscularis of the uterus, the outer layer to the stratum perivasculare uteri and the tunica muscularis of the oviduct known from olden times to the stratum submucosum of the uterus.

The mucasa of the oviduct consists of a thin propria of delicate connective tissue containing spindle-formed fibrocytes and a simple epithelium, of which the cells are either ciliated or not, as in the epithelium of the uterus. The only difference lies in that well-developed mucous folds are found in the nucosa of the oviduct.

Thus, the histological structure of the oviduct, except in the smallness of its size, is the same with that of the uterus - a similarity that may be easy to understand when we recall the identical embryological origin of the two organs. The none too rare frequency of salpingocyesis 
also is sufficient to suggest the similar structure of these organs.

The nerve bundles distributed to the oviduct come first into the blood vessel layer of the mesosalpinx. These bundles consist mainly of vegetative fibres but contain a small number of sensory fibres 10o. They send in their courses in the blood vessel layer many fine branches out into the outer smooth muscle tissue. These branches undergo further ramification and mutual anastomosis, forming net-works of fine fibres, finally developing into full STÖHR's terminal reticula, which come into control by contact over the muscle fibres. Similar formations are observed in the muscle tissue of the tubules of the epoöphoron as well, and in the perivascular plexus around the blood vessels, in particular, the arteries, the vegetative fibres always ending in similar terminal reticula.

Terminations of sensory fibres are found in the mesosalpinx. These consist in unbranched or simple branched terminations of fibres showing characteristic winding and change in size, and are formed around blood vessels, especially around small veins, and frequently in the muscle tissue and also in the subserosa. No corpuscular terminations were found in the mesosalpinx.

The small nerve bundles going throngh the nesosalpins into the oviduct first come into the stratum vaseulare of the muscularis, branch out i ito fine rami, anastomose among themselves, and form rather poorly developed plexus, which contains no nerve cells. This plexus sends out numerous nerve branches both outwards into the stratum privasculare and inwards into the stratum submucosum. Some of the nerve fibres run throngh the stratum submucosum further into the mucosa, to form illdeveloped plexus in its propria. The vegetative fibres in the muscularis as well as in the mucosa always end in terminal reticula, as was in the case of the mesosalpinx.

Simple sensory terminations are frequently found in the oviduct too. SAKAGUCHI has detected such terminations only in the small blood vessels on extremely rare occasions, but in my study, I found them formed rather frequently not only in the blood vessels, but also in the muscle tissue, in the subserosa and in the mucous membrane. I failed, however, in once demonstrating the existence of corpuscular terminations as reported by some past researchers. No sensory intraepithelial fibres, as allegedly discovered in the oviduet by GAWRONSKY could be detected either.

The myelinatcd sensory fibres, in the oviduct as in the mesosalpinx, after losing their myelin sheaths, run winding courses while showing characteristic change in size and end in unbranched or simple branched terminations. The terminations are much of ener formed around the blood vessels, particularly, the veins, than in the muscle tissue. Their terminal fibres usually end in blunt or sharp ponits, but in some cases loops are 
formed by them before ending.

\section{内容自抄。}

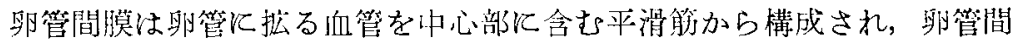

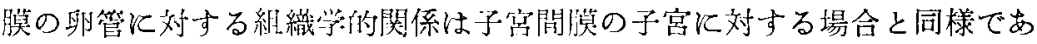

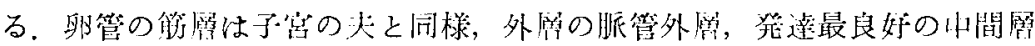

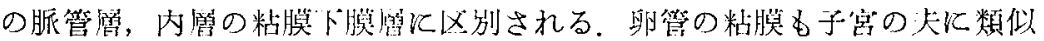

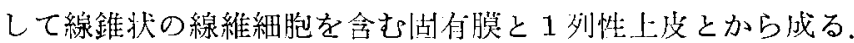

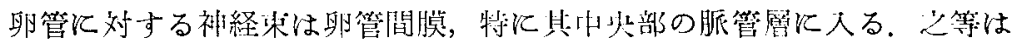
専ら植物線維から成るが，尚拈少量の知覚線維を含み，䈤組織飞刘し多数 の微細枝を出す，植物線維は何れもStöhr 氏終網となり，禁ら杵線維に対 して接触的主舞関係を示す。

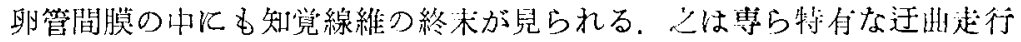
と太さの変化とを示す線維から成る非分岐性:灭び単純性分岐性終末で表わ

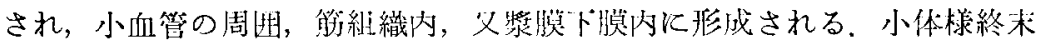
は発見されない。

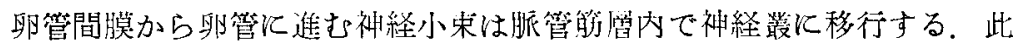

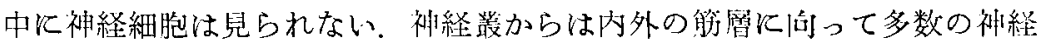
枝が出る，又粘膜の中にも微細枝の進入を見る，植物線維は卵管内でも終 網に終っている.

卵管内にも単純な知覚終末が発見される。本終末卵管間膜に見られる

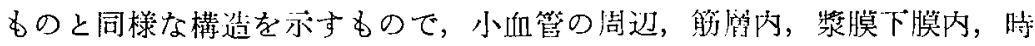
には粘膜內にる形成される，2-3の学者が兒たという小体様終末及び上 皮内線維は何処飞与発見されない。

\section{References.}

Coryllos: Rev, franç. de gynécol. et d'obstétr. 27 (1913). -- Dahl : Z. Geburtsh. u. Gynäk. 78 (1916). -- Ebner: Mschr. Geburtsh. 18 (1903). Gawronsky : Arch. Gynäk. 47 (1894). - Harting : Z. Kellforsch. 9 (1929).-Herff: Z. Geburtsh. u. Gynäk. 24 (1892). - Koestlin: Fortschr. Med. 12 (1894). - Landau Gynécol. et obstétr. 51 (1952). - Mabuchi : Mitt. med. Fak. Univ. Tokyo. 31 (1924). - Ries: Z. Geburtsh. u. Gynäk. 62 (1908). - Schröder: Möllendorffs Handbuch der mikroskopischen Anatomie des Menschen. Bd. 7, Tl. 1. Berlin, J. Springer, 1930, - Stöhr: Mikroskopische Anatomie des vegetativen Nervensystems. Berlin, J. Springer, 1928. - Sakaguchi: J. orient. Med. 30 (1939). 